\title{
Prescription of opioids for breathlessness in end-stage COPD: a national population-based study
}

This article was published in the following Dove Press journal:

International Journal of COPD

21 October 2016

Number of times this article has been viewed

\author{
Zainab Ahmadi ${ }^{1,2}$ \\ Eva Bernelid ${ }^{2}$ \\ David C Currow ${ }^{3}$ \\ Magnus Ekström ${ }^{1-3}$ \\ 'Department of Clinical Sciences, \\ Division of Respiratory Medicine and \\ Allergology, Lund University Hospital, \\ Lund, ${ }^{2}$ Department of Medicine, \\ Blekinge Hospital, Karlskrona, Sweden; \\ ${ }^{3}$ Discipline, Palliative and Supportive \\ Services, Flinders University, Adelaide, \\ SA, Australia
}

Correspondence: Zainab Ahmadi Department of Clinical Sciences, Division of Respiratory Medicine and Allergology, Lund University Hospital, Klinikgatan I8, SE-22I 00 Lund, Sweden

Tel +46 $46 \quad 17 \quad 1000$

Email zai.ahmd@gmail.com
Background: Low-dose opioids can relieve breathlessness but may be underused in late-stage COPD due to fear of complications, contributing to poor symptom control.

Objectives: We aimed to study the period prevalence and indications of opioids actually prescribed in people with end-stage COPD.

Methods: The study was a longitudinal, population-based study of patients starting long-term oxygen therapy (LTOT) for COPD between October 1, 2005 and June 30, 2009 in Sweden. A random sample $(n=2,000)$ of their dispensed opioid prescriptions was obtained from the national Prescribed Drugs Register from 91 days before starting LTOT until the first of LTOT withdrawal, death, or study end (December 31, 2009). We analyzed medication type, dispensed quantity, date of dispensing, and indications categorized as pain, breathlessness, other, or unknown.

Results: In total, 2,249 COPD patients (59\% women) were included. During a median follow-up of 1.1 (interquartile range $0.6-2.0)$ years, 1,034 patients $(46 \%)$ were dispensed $\geq 1$ opioid prescription ( $\mathrm{N}=13,722$ prescriptions). The most frequently prescribed opioids were tramadol (23\%), oxycodone $(23 \%)$, morphine (16\%), and codeine (16\%). Average dispensed quantity was 9.3 (interquartile range 3.7-16.7) defined daily doses per prescription. In the random sample, the most commonly stated indication was pain (97\%), with only $2 \%$ for breathlessness and $1 \%$ for other reasons.

Conclusion: Despite evidence that supported the use of opioids for the relief of breathlessness predating this study, opioids are rarely prescribed to relieve breathlessness in oxygen-dependent COPD, potentially contributing to less-than-optimal symptom control. This study creates a baseline against which to compare future changes in morphine prescribing in this setting.

Keywords: COPD, symptoms, breathlessness, opioids, prescriptions, LTOT

\section{Introduction}

COPD is a leading cause of mortality worldwide, and is associated with high burden of symptoms, often poorly controlled in advanced disease stages. ${ }^{1-4}$ The prevalence and severity of breathlessness are higher in end-stage COPD than in advanced lung cancer, both during the final year of life and in the terminal weeks and days near death. ${ }^{5,6}$ Despite long-term oxygen therapy (LTOT), most COPD patients suffer from breathlessness at rest or on minimal exertion that greatly limits even the basic activities of daily living..$^{7-9}$ Breathlessness that persists at rest or on minimal exertion despite optimal treatment of the underlying disease(s) is termed "refractory breathlessness." 10,11

Opioids have a growing evidence base for decreasing refractory breathlessness in advanced COPD. ${ }^{10,12}$ Jennings et al concluded in a Cochrane meta-analysis that 
low doses of oral sustained-release morphine can reduce chronic refractory breathlessness, ${ }^{12}$ which was confirmed by an adequately powered crossover trial in $2003 .{ }^{10}$

Clinicians may, however, be reluctant to prescribe opioids due to a fear of adverse events including confusion, falls, and respiratory depression in patients with respiratory compromise. ${ }^{13}$ Among stable outpatients with advanced COPD, 94\% reported moderate to severe breathlessness but only $2 \%$ used opioids, such as morphine. ${ }^{13}$ In palliative care, only one-fourth of COPD patients received opioids during their last 6 months of life, compared to half of the patients with lung cancer. ${ }^{14}$

No study has evaluated the indications for actual prescribed opioids, and data are limited on the temporal trends and prescription as death approaches. A recent study reported that opioid therapy, mostly short-term, was commonly used in COPD but did not analyze the indications for opioid use. ${ }^{15}$ Underuse of opioids for breathlessness in severe COPD could contribute to insufficient symptom control and unnecessary suffering.

The aim of this study was to evaluate the indications, medication types, and temporal patterns of opioid prescription in severe oxygen-dependent COPD.

\section{Materials and methods Design and participants}

This was an observational, population-based study of patients aged 45 years or older who started LTOT for COPD in the Swedish Register for Respiratory Failure between October 1, 2005 and June 30, 2009. The database was used in a recent safety study of opioids. ${ }^{16}$

\section{Data sources}

The Swedish Register for Respiratory Failure prospectively includes patients starting LTOT in Sweden with a nationwide coverage of approximately $85 \% .{ }^{17}$ It contains physiological data including arterial blood gas tensions when breathing air and oxygen, body mass index, World Health Organization (WHO) performance status, ${ }^{18}$ and forced expiratory volume in 1 second registered at the start of LTOT. Details of the register have been published. ${ }^{19}$

Data on all dispensed outpatient prescriptions were obtained from the Swedish Prescribed Drugs Register ${ }^{20}$ during the study period, which was from 91 days before the start of LTOT until the first of LTOT withdrawal, death, or study end (December 31, 2009). Drugs were categorized according to the Anatomical Therapeutic Chemical Classification System (ATC codes) as previously described. ${ }^{16}$
Vital status was obtained from the Swedish Causes of Death Register.

\section{Opioid prescriptions}

A random sample $(n=2,000)$ of the cohort's dispensed opioid prescriptions during the study period was derived from the database using the commando runiform in the statistical package Stata, version 13 (StataCorp LP; College Station, TX, USA). The random sample was analyzed in relation to medication type, dispensed quantity as WHO defined daily doses, ${ }^{21}$ date of dispensing, and free-text indication. Each indication was reviewed by a respiratory physician and categorized as pain, breathlessness, other, or unknown (insufficient information to identify an indication). Each prescription could have multiple indications and could include both a regular and an "as-needed" dose. In Sweden, the stated free-text indications are decided entirely by the prescribing physician and do not undergo external review by the pharmacy or clinic. Analysis of primary interest was the period prevalence of opioid prescriptions during the follow-up period.

\section{Ethics}

Participants provided their verbal consent when registered in Swedevox, and the consent procedure and the study were approved by the Lund University Research Ethics Committee (157/2007 and 350/2008), the Swedish National Board of Health and Welfare, and the Data Inspection Board.

\section{Statistical analyses}

Baseline characteristics were summarized as counts and percentages for categorical variables, mean values with standard deviation or median with interquartile range (IQR) or range for normally and nonnormally distributed continuous variables, respectively. Differences were tested using a $t$-test for continuous variables and chi-square test for unpaired categorical data. All tests were two sided, and statistical significance was defined as $P<0.05$. Statistical analyses were conducted using Stata version 12.1 (StataCorp LP, College Station, TX, USA).

\section{Results}

\section{Participants}

A total of 2,249 COPD patients (59\% women) were included prospectively and followed-up for a median 1.1 years (IQR 0.6-2.0). During the study period, 1,034 patients (46\%) were dispensed at least one prescription of an opioid (in total 13,722 dispensed opioid prescriptions). As shown in Table 1, patients who were prescribed opioids were aged $74 \pm 8$ years, 
Table I Characteristics of oxygen-dependent COPD patients who were prescribed opioids

\begin{tabular}{|c|c|c|c|}
\hline Characteristic & $\begin{array}{l}\text { Total } \\
(n=I, 034)\end{array}$ & $\begin{array}{l}\text { Patients with known indication } \\
\text { for prescription }(n=273)\end{array}$ & $\begin{array}{l}\text { Patients with unknown indication } \\
\text { for prescription }(n=302)\end{array}$ \\
\hline Age (years) & $74.6 \pm 8$ & $72.7 \pm 8$ & $75.9 \pm 8$ \\
\hline Females, n (\%) & $684(66)$ & $188(69)$ & $217(72)$ \\
\hline $\mathrm{PaO}_{2}$ air $(\mathrm{kPa})$ & $6.6 \pm 0.87$ & $6.7 \pm 0.86$ & $6.4 \pm 0.86$ \\
\hline $\mathrm{PaCO}_{2}$ air $(\mathrm{kPa})$ & $6.3 \pm 1.2$ & $6.3 \pm 1.1$ & $6.4 \pm 1.2$ \\
\hline \multicolumn{4}{|l|}{ WHO status, n (\%) } \\
\hline 0 & $49(5)$ & $17(6)$ & II (4) \\
\hline 1 & $379(37)$ & $114(42)$ & $84(28)$ \\
\hline 2 & $344(33)$ & $85(31)$ & $110(36)$ \\
\hline 3 & $145(14)$ & $22(8)$ & $56(18)$ \\
\hline 4 & $20(2)$ & I (0) & $8(3)$ \\
\hline $\mathrm{FEV}_{1}(\mathrm{~L})$ & $0.83 \pm 0.5$ & $0.86 \pm 0.5$ & $0.80 \pm 0.5$ \\
\hline $\mathrm{FEV}_{1}$ (\% of predicted) & $34 \pm 17.3$ & $34 \pm 17.9$ & $33 \pm 15.4$ \\
\hline Follow-up (days) & $442(23 I-754)$ & $568(262-834)$ & 545 (268-749) \\
\hline
\end{tabular}

Notes: Data presented as mean \pm SD unless stated otherwise. $\mathrm{N}$ (\%) of missing for $\mathrm{PaO}_{2}, 146$ (14); $\mathrm{PaCO}_{2}, 15 \mathrm{I}$ (I5); WHO status, 97 (9); FEV, 403 (39); FEV (\% of predicted), 453 (44). aMedian (first quartile-third quartile).

Abbreviations: $\mathrm{FEV}_{1}$, forced expiratory volume in I second; $\mathrm{PaO}_{2}$, arterial blood gas tension of oxygen on breathing air; $\mathrm{PaCO}_{2}$, arterial blood gas tension of carbon dioxide on breathing air; SD, standard deviation; WHO, World Health Organization.

were mostly women (66\%), and $70 \%$ were mostly ambulatory with WHO status $1-2$ at LTOT start. The random sample of $2,000(15 \%)$ of the opioid prescriptions was dispensed by 575 patients.

\section{Types of opioids}

The most frequently prescribed opioids were tramadol (23\%), oxycodone $(23 \%)$, morphine (16\%), and codeine (16\%), as shown in Table 2. The average dispensed quantity was 9.3 (IQR 3.7-16.7) defined daily doses per prescription. Of the opioid prescriptions, 417 (21\%) included an as-needed dose (Table 2). No nebulized opioids were prescribed. The indication was present in $33 \%(n=662)$ of the opioid prescriptions and absent in $67 \%(n=1338)$ of the opioid prescriptions

Table 2 Opioid prescriptions in oxygen-dependent COPD

\begin{tabular}{ll}
\hline Prescriptions & $\begin{array}{l}\text { Random sample } \\
\mathbf{n}=\mathbf{2 , 0 0 0}\end{array}$ \\
\hline Substance, n (\%) & \\
Codeine & $318(16)$ \\
Dextropropoxifen & $270(14)$ \\
Fentanyl & $99(5)$ \\
Morphine & $314(16)$ \\
Oxycodone & $449(22)$ \\
Tramadol & $459(23)$ \\
Others & $91(4)$ \\
DDDs per prescription & \\
Included “as-needed" dose, $\mathrm{n}(\%)$ & $9.3(3.7-16.7)$ \\
\hline
\end{tabular}

Notes: A random sample of 2,000 (15\%) of the total 13,722 opioid prescriptions was analyzed regarding medication type, dispensed amount, date of dispensation, and indication (free text). aMedian (first quartile-third quartile).

Abbreviation: DDDs, defined daily doses.
(Table 3). Characteristics were similar between the patients whose indications for opioids were known compared to those with unknown indications (Table 1).

\section{Temporal patterns of indications}

Table 3 shows indications for the prescriptions of opioids before and after the start of LTOT. The vast majority of the stated indications were pain (97\%), with only $2 \%$ for breathlessness and $1 \%$ for other reasons among the prescriptions with known indications. Prescriptions with dual indications (pain and breathlessness) occurred in only $0.7 \%(n=5)$ of the known indications. During the last 6 months of the patients' lives, the period prevalence of opioid prescriptions for breathlessness was only 4\% (Table 4).

Opioids were prescribed predominantly among patients with WHO performance status 1-2 (Table 5).

Figure 1 shows the temporal pattern of opioid prescriptions during follow-up by indication. Pain was the predominant indication throughout the study period. Breathlessness as an indication increased slightly during follow-up but the absolute numbers were low.

\section{Discussion}

\section{Key findings}

In oxygen-dependent COPD, breathlessness was an indication in less than $2 \%$ of opioid prescriptions and only $4 \%$ in the last 6 months of life. Among patients, $46 \%$ took an opioid during follow-up. Of the stated indications, the vast majority was pain (97\%) and as many as $67 \%$ of opioid prescriptions lacked any information on the indication. 
Table 3 Indications of 2,000 random opioid prescriptions among 575 patients with oxygen-dependent COPD

\begin{tabular}{lllll}
\hline Indication, $\mathbf{n}(\%)$ & Overall & $\begin{array}{l}\text { 6 months } \\
\text { before LTOT }\end{array}$ & $\begin{array}{l}\text { First } \mathbf{6} \text { months } \\
\text { of LTOT }\end{array}$ & $\begin{array}{l}\text { Last } \mathbf{6} \text { months } \\
\text { of LTOT }\end{array}$ \\
\hline Known indication & $662(33)$ & $153(39)$ & $188(37)$ & $215(30)$ \\
Pain & $642(97)$ & $150(98)$ & $183(97)$ & $206(96)$ \\
Breathlessness & $13(2)$ & $1(0.7)$ & $4(2)$ & $6(3)$ \\
Other & $7(1)$ & $2(1)$ & $1(0.5)$ & $3(1)$ \\
Unknown indication & $1,338(67)$ & $236(61)$ & $325(63)$ & $508(70)$ \\
\hline
\end{tabular}

Note: Percentages might not sum to 100 because of rounding.

Abbreviation: LTOT, long-term oxygen therapy.

\section{Strengths and limitations}

Strengths of the present study include its national population-based design with complete longitudinal data on all dispensed outpatient opioid prescriptions and vital status nationwide. National registry data enabled complete follow-up in these frail patients with advanced disease. The use of a randomized prescription sample enabled analysis of the free-text indications, and the timing of prescription was analyzed in relation to LTOT and death.

A possible limitation was that a high proportion of prescriptions lacked a stated indication. This would probably not lead to bias because the opioid indication is not externally reviewed and does not affect the price or the patient's ability to dispense the opioid prescription in Sweden. It also reflects clinical reality and is an important finding in its own right by identifying an area of possible improvement in clinical practice. Clear information regarding the indication and aim of the treatment should be written on all prescriptions, especially regarding sick elderly patients and when informal caretakers are involved. Prescription data did not include opioids given in hospital, but this is unlikely to substantially change the relations between the treatment indications. Another possible limitation is that the study included data between 2005 and 2009. However, evidence that supported the use of opioids for the relief of breathlessness was already available from a Cochrane meta-analysis published in $2002^{12}$ and an adequately powered trial published in $2003 .{ }^{10} \mathrm{We}$ did not have patient-reported data including breathlessness

Table 4 Prescribed opioids at LTOT start versus before death in oxygen-dependent COPD patients who died $(n=278)$

\begin{tabular}{lll}
\hline Indication, $\mathbf{n}(\%)$ & $\begin{array}{l}\text { First } 6 \text { months } \\
\text { of LTOT }\end{array}$ & $\begin{array}{l}\text { Last } 6 \text { months } \\
\text { of life }\end{array}$ \\
\hline Known indication & $75(28)$ & $106(29)$ \\
Pain & $71(95)$ & $101(95)$ \\
Breathlessness & $3(4)$ & $4(4)$ \\
Other & I (I) & I (1) \\
Unknown indication & I9I (72) & $265(71)$ \\
\hline
\end{tabular}

Abbreviation: LTOT, long-term oxygen therapy. or quality of life scores to further characterize patients in this study.

Given the evidence of the efficacy of opioids for breathlessness, ${ }^{10,12,16,22}$ the study design, and the striking difference in prescribing for pain ( $97 \%$ of prescriptions) and breathlessness $(2 \%)$, the finding that opioids are rarely used for refractory breathlessness in advanced and end-stage COPD likely has high validity.

\section{Relation to current evidence}

Patients with advanced and oxygen-dependent COPD are known to suffer from high levels of breathlessness despite LTOT, both in outpatients and at the end of life. ${ }^{6-9}$ Opioids have been reported to be less prescribed near death in advanced COPD than in lung cancer, despite the presence of more breathlessness in COPD and similar rates of pain. ${ }^{6,14}$

The current findings are consistent with a Dutch study that chest physicians rarely prescribed opioids for refractory breathlessness to outpatients with advanced COPD. ${ }^{23}$ The most frequent barriers to opioid prescription were the physician's fear of possible serious adverse events, including respiratory depression and resistance of some patients. ${ }^{23}$ Although more research is needed, the evidence to date supports the safety of low-dose opioids for symptomatic treatment in advanced diseases including COPD. This evidence consists of a Cochrane meta-analysis, ${ }^{12}$ a systematic review, ${ }^{24}$ a randomized trial, ${ }^{10}$ and several studies. ${ }^{16,22}$ Sustained-release morphine should be considered as a first line treatment and should be initiated at a low dose regularly and titrated upward over days and weeks, balancing beneficial and adverse effects. ${ }^{25,26}$ All treatments assume adequate follow-up of the patient's clinical condition and symptoms, including proper prophylaxis and treatment for expected effects such as opioid-related constipation. ${ }^{10,25}$ Opioid side effects include initial nausea, worsened constipation, or dizziness, which have been reversible upon dose reduction or discontinuation. ${ }^{16}$ There have been no reported serious adverse events related to titrated low-dose opioids, 
Table 5 Indications of opioid prescriptions by WHO performance status in oxygen-dependent COPD

\begin{tabular}{|c|c|c|c|c|c|}
\hline Indication, n (\%) & WHO status 0 & WHO status I & WHO status 2 & WHO status 3 & WHO status 4 \\
\hline Known indication & $38(45)$ & $273(42)$ & $224(32)$ & $55(17)$ & $2(7)$ \\
\hline Pain & $38(100)$ & 269 (99) & $211(94)$ & $53(96)$ & $2(100)$ \\
\hline Breathlessness & 0 & $2(0.7)$ & $8(4)$ & $2(4)$ & 0 \\
\hline Other & 0 & $2(0.7)$ & $5(2)$ & 0 & 0 \\
\hline Unknown indication & $47(55)$ & $374(58)$ & $485(68)$ & $275(83)$ & $28(93)$ \\
\hline
\end{tabular}

Notes: Percentages might not sum to 100 because of rounding. WHO status: 0 , fully active, able to carry out all pre-disease activities without restriction; I, restricted in physically strenuous activity but ambulatory and able to carry out work of a light or sedentary nature, eg, light house work, office work; 2 , ambulatory and capable of all selfcare but unable to carry out any work activities, and up and about more than $50 \%$ of waking hours; 3 , capable of only limited selfcare, confined to bed or chair more than $50 \%$ of waking hours; 4 , completely disabled, incapable of any selfcare, totally confined to bed or chair.

Abbreviation: WHO, World Health Organization.

including no case of respiratory depression. ${ }^{12,16,22,24}$ A study using the present database found that low-dose opioids were not associated with increased rates of hospitalization or death in patients with severe oxygen-dependent COPD. ${ }^{16}$ In a pharmacovigilance study of 83 patients who received 10-30 mg oral morphine per day, no episodes of respiratory depression or hospitalizations were reported up to 3 months. ${ }^{22}$ A recent meta-analysis (16 studies; 271 patients) reported that opioids safely improved breathlessness in severe COPD. ${ }^{24}$ The findings from this meta-analysis are consistent with those of Jennings et al. ${ }^{12}$ Rocker et al reported that patients experienced beneficial effects from opioid therapy for breathlessness that sustained over months. ${ }^{27}$ The present study suggests that, despite the high symptom burden ${ }^{6}$ and the
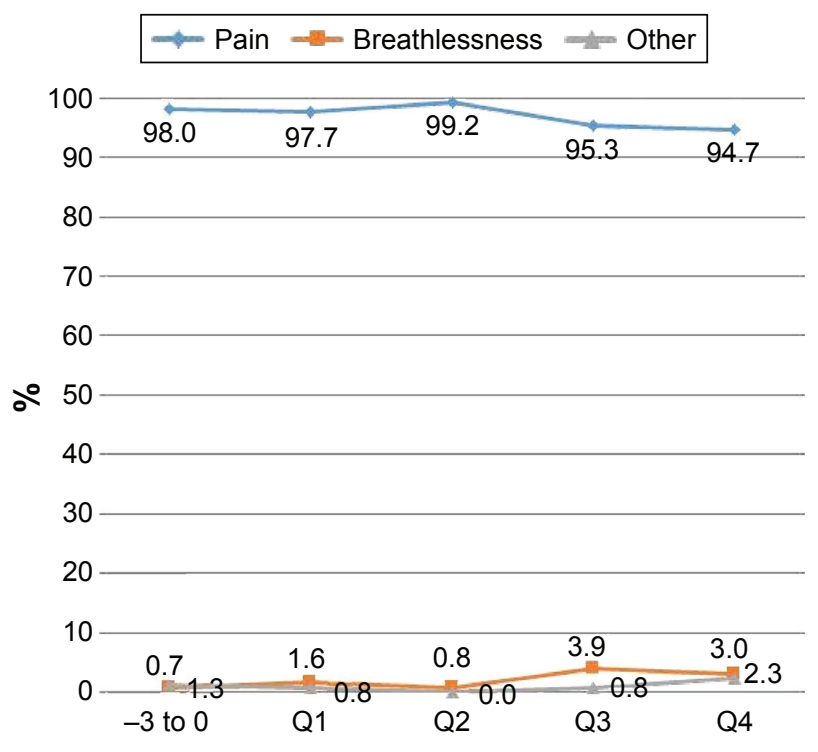

Time period in relation to LTOT

Figure I Trend for stated indications of opioid prescriptions in 575 patients with oxygen-dependent COPD.

Notes: Percentage of dispensed opioid prescriptions with the indication for pain, breathlessness, or other (of the prescriptions with known indication; $\mathrm{N}=662 ; 33 \%$ ). Time periods are 3 months before starting LTOT ( -3 to 0 months), and each quartile (QI-Q4) of follow-up during LTOT. available safety data, ${ }^{12,16,22,24}$ there is a widespread reluctance to prescribe opioids for breathlessness in advanced COPD.

\section{What this study adds}

This is, to the authors' knowledge, the first study looking at the indications for prescribing opioids in severe COPD. This study shows that patients with oxygen-dependent COPD are treated with opioids; $46 \%$ of patients were dispensed at least one prescription during follow-up. Pain was the dominating opioid indication (97\%), and breathlessness was the indication in only $2 \%$ of the prescriptions. Although breathlessness as an indication increased, slightly during follow-up, absolute numbers were low and during the last 6 months of life, only $4 \%$ of opioid prescriptions were for breathlessness. These findings further support undertreatment of breathlessness both for symptom relief and at the end of life. ${ }^{6}$

\section{Implications and the future}

This study forms a crucial baseline against which to evaluate temporal trends in opioid prescribing for COPD as the evidence base continues to evolve. Research is needed to inform and implement evidence-based opioid treatment for the relief of refractory breathlessness in severe COPD. Large-scale longitudinal studies are needed to evaluate adverse effects and the net clinical benefit of opioids in clinical practice. ${ }^{16,28}$ Initiatives for implementing evidencebased treatment for symptom relief are warranted in severe respiratory diseases.

For clinicians, this study identifies potential improvement opportunities in the management of chronic refractory breathlessness. Changing the threshold at which people experience breathlessness is likely to have important implications for activities of daily living. It is likely that people exert themselves to the same level of breathlessness, and if this takes longer or more intense exertion to reach, then people are likely to be more active, therefore breaking the cycle of deconditioning. Structured measurement of 
the breathlessness severity in routine care is important in evidence-based symptomatic treatment. ${ }^{29}$ Given their growing evidence of efficacy and safety, low-dose opioids, after careful initiation and titration, can be prescribed with better confidence for the relief of refractory breathlessness in advanced COPD. ${ }^{30,31}$ Another important finding is that more than half of the opioid prescriptions lacked any written indication. Clear oral and written information on why opioid is given and on the aim of the therapy is likely important for the safety of the therapy, compliance, and symptom control in these often elderly, frail, and often multi-morbid patients with end-stage respiratory diseases.

\section{Conclusion}

In severe oxygen-dependent COPD, almost half of patients were treated with opioids at some point, largely for pain $(97 \%)$. Breathlessness was a rare indication for opioids $(2 \%)$, even near death.

\section{Acknowledgments}

We thank all the physicians and nurses who collected the data and cared for the patients. This study was funded by unrestricted grants from the Scientific Committee of Blekinge County Council, Swedish Society of Medicine, Swedish Respiratory Society, Swedish Heart-Lung Foundation, and the Wera and Emil Cornell Foundation.

\section{Author contributions}

ME had full access to all the data in the study and takes full responsibility for the integrity of the data and the accuracy of the data analysis. DCC, ME, and ZA conceptualized and designed the study; $\mathrm{EB}$ and $\mathrm{ME}$ were responsible for the acquisition of the data; EB, ME, and ZA analyzed the data; DCC, ME, and ZA interpreted the data; ME and ZA drafted the article; and $\mathrm{DCC}, \mathrm{EB}, \mathrm{ME}$, and $\mathrm{ZA}$ revised important intellectual content and approved the version to be published.

\section{Disclosure}

The authors report no conflicts of interest in this work.

\section{References}

1. Lozano R, Naghavi M, Foreman K, et al. Global and regional mortality from 235 causes of death for 20 age groups in 1990 and 2010: a systematic analysis for the Global Burden of Disease Study 2010. Lancet. 2012; 380(9859):2095-2128.

2. Walke LM, Byers AL, Tinetti ME, Dubin JA, McCorkle R, Fried TR. Range and severity of symptoms over time among older adults with chronic obstructive pulmonary disease and heart failure. Arch Intern Med. 2007;167(22):2503-2508.
3. Johnson MJ, Bowden JA, Abernethy AP, Currow DC. To what causes do people attribute their chronic breathlessness? A population survey. J Palliat Med. 2012;15(7):744-750.

4. Müllerová H, Lu C, Li H, Tabberer M. Prevalence and burden of breathlessness in patients with chronic obstructive pulmonary disease managed in primary care. PLoS One. 2014;9(1):e85540.

5. Moens K, Higginson IJ, Harding R. EURO IMPACT. Are There differences in the prevalence of palliative care-related problems in people living with advanced cancer and eight non-cancer conditions? A systematic review. J Pain Symptom Manage. 2014;48(4):660-677.

6. Ahmadi Z, Lundström S, Janson C, et al. End-of-life care in oxygendependent COPD and cancer: a national population-based study. Eur Respir J. 2015;46(4):1190-1193.

7. Elkington H, White P, Addington-Hall J, Higgs R, Edmonds P. The healthcare needs of chronic obstructive pulmonary disease patients in the last year of life. Palliat Med. 2005;19(6):485-491.

8. Gulbas G, Gunen H, In E, Kilic T. Long-term follow-up of chronic obstructive pulmonary disease patients on long-term oxygen treatment. Int J Clin Pract. 2012;66(2):152-157.

9. Law S, Boyd S, Macdonald J, Raeside D, Anderson D. Predictors of survival in patients with chronic obstructive pulmonary disease receiving long-term oxygen therapy. BMJ Support Palliat Care. 2014. doi:10.1136/bmjspcare-2012-000432.

10. Abernethy AP, Currow DC, Frith P, Fazekas BS, McHugh A, Bui C. Randomised, double blind, placebo controlled crossover trial of sustained release morphine for the management of refractory dyspnoea. BMJ. 2003;327(7414):523-528.

11. Parshall MB, Schwartzstein RM, Adams L, et al. An official American Thoracic Society statement: update on the mechanisms, assessment, and management of dyspnea. Am J Respir Crit Care Med. 2012;185(4): 435-452.

12. Jennings AL, Davies AN, Higgins JP, Gibbs JS, Broadley KE. A systematic review of the use of opioids in the management of dyspnoea. Thorax. 2002;57(11):939-944.

13. Janssen DJ, Spruit MA, Uszko-Lencer NH, Schols JM, Wouters EF. Symptoms, comorbidities, and health care in advanced chronic obstructive pulmonary disease or chronic heart failure. J Palliat Med. 2011; 14(6):735-743.

14. Au DH, Udris EM, Fihn SD, McDonell MB, Curtis JR. Differences in health care utilization at the end of life among patients with chronic obstructive pulmonary disease and patients with lung cancer. Arch Intern Med. 2006;166(3):326-331.

15. Vozoris NT, Wang X, Fischer HD, et al. Incident opioid drug use among older adults with chronic obstructive pulmonary disease: a populationbased cohort study. Br J Clin Pharmacol. 2015;81(1):161-170.

16. Ekström MP, Bornefalk-Hermansson A, Abernethy AP, Currow DC. Safety of benzodiazepines and opioids in very severe respiratory disease: national prospective study. BMJ. 2014;348:g445.

17. Swedish National Register for Respiratory Failure (Swedevox). Annual Report. 2014. Available from: www.ucr.uu.se/swedevox/. Accessed October 9, 2015.

18. Oken MM, Creech RH, Tormey DC, et al. Toxicity and response criteria of the Eastern Cooperative Oncology Group. Am J Clin Oncol. 1982; 5(6):649-655.

19. Ekström MP, Hermansson AB, Strom KE. Effects of cardiovascular drugs on mortality in severe chronic obstructive pulmonary disease. Am J Respir Crit Care Med. 2013;187(7):715-720.

20. Wettermark B, Hammar N, Fored CM, et al. The new Swedish Prescribed Drug Register - opportunities for pharmacoepidemiological research and experience from the first six months. Pharmacoepidemiol Drug Saf. 2007;16(7):726-735.

21. WHO Collaborating Centre for Drug Statistics Methodology. Guidelines for ATC Classification and DDD Assignment 2011. WHO; 2010.

22. Currow DC, McDonald C, Oaten S, et al. Once-daily opioids for chronic dyspnea: a dose increment and pharmacovigilance study. J Pain Symptom Manage. 2011;42(3):388-399. 
23. Janssen DJ, de Hosson SM, bij de Vaate E, Mooren KJ, Baas AA. Attitudes toward opioids for refractory dyspnea in COPD among Dutch chest physicians. Chron Respir Dis. 2015;12(2):85-92.

24. Ekström M, Nilsson F, Abernethy AA, Currow DC. Effects of opioids on breathlessness and exercise capacity in chronic obstructive pulmonary disease: a systematic review. Ann Am Thorac Soc. 2015;12(7): 1079-1092.

25. Rocker G, Horton R, Currow D, Goodridge D, Young J, Booth S. Palliation of dyspnoea in advanced COPD: revisiting a role for opioids. Thorax. 2009;64(10):910-915.

26. Currow DC, Quinn S, Greene A, Bull J, Johnson MJ, Abernethy AP. The longitudinal pattern of response when morphine is used to treat chronic refractory dyspnea. J Palliat Med. 2013;16(8):881-886.

27. Rocker GM, Simpson AC, Joanne Young B, et al. Opioid therapy for refractory dyspnea in patients with advanced chronic obstructive pulmonary disease: patients' experiences and outcomes. CMAJ Open. 2013;1(1):E27-E36.
28. Johnson MJ, Abernethy AP, Currow DC. Gaps in the evidence base of opioids for refractory breathlessness. A future work plan? J Pain Symptom Manage. 2012;43(3):614-624.

29. Mularski RA, Campbell ML, Asch SM, et al. A review of quality of care evaluation for the palliation of dyspnea. Am J Respir Crit Care Med. 2010;181(6):534-538.

30. Ekström M, Bornefalk-Hermansson A, Abernethy A, Currow D. Lowdose opioids should be considered for symptom relief also in advanced chronic obstructive pulmonary disease (COPD). Evid Based Med. 2015;20(1):39.

31. Ekström MP, Abernethy AP, Currow DC. The management of chronic breathlessness in patients with advanced and terminal illness. BMJ 2015;349:g7617.
International Journal of COPD

\section{Publish your work in this journal}

The International Journal of COPD is an international, peer-reviewed journal of therapeutics and pharmacology focusing on concise rapid reporting of clinical studies and reviews in COPD. Special focus is given to the pathophysiological processes underlying the disease, intervention programs, patient focused education, and self management protocols

\section{Dovepress}

This journal is indexed on PubMed Central, MedLine and CAS. The manuscript management system is completely online and includes a very quick and fair peer-review system, which is all easy to use. Visit http://www.dovepress.com/testimonials.php to read real quotes from published authors.

Submit your manuscript here: http://www.dovepress.com/international-journal-of-chronic-obstructive-pulmonary-disease-journal 